Metals and Ceramics Division

CRADA Final Report

for CRADA Number ORNL97-0459

OAK RIDGE NATIONAL LABORATORY

LecknEED WATTE

\section{HYDROXYLAPATITE OTOLOGIC IMPLANTS}

\author{
A.D. McMillan, R.J. Lauf \\ Oak Ridge National Laboratory \\ B. Beale, R. Johnson \\ Smith \& Nephew Richards; Inc.
}

Date Published - January 2000

Prepared by the

OAK RIDGE NATIONAL LABORATORY

Oak Ridge, Tennesee 37831 managed by

LOCKHEED MARTIN ENERGY

RESEARCH CORPORATION

For the

U.S. DEPARTMENT OF ENERGY under contract DE-AC05-960R22464

\author{
APPROVED FOR PUBLIC RELEASE \\ UNLIMITED DISTRIBUTION
}





\section{CRADA Final Report \\ for \\ CRADA Number ORNL97-0459}

Hydroxylapatite Otologic Implants

A.D. McMillan, R.J. Lauf

Oak Ridge National Laboratory

B. Beale, R. Johnson

Smith \& Nephew Richards, Inc.

Prepared by the Oak Ridge National Laboratory, Oak Ridge, Tennesee 37831

Managed by

Lockheed Martin Energy Research Corporation

For the

U.S. Department of Energy

Under contract DE-AC05-960R22464

Approved for Public release;

distribution is unlimited.

This work was supported through a CRADA with Smith \& Nephew Richards, Inc., Bartlett, TN, sponsored by the Laboratory Technology Research Program, Office of Science, U.S. Department of Energy, under contract DE-AC05-960R22464 with Oak Ridge National Laboratory, managed by Lockheed Martin Energy Research Corporation. 


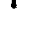




\title{
Hydroxylapatite Otologic Implants
}

\author{
CRADA $97-0459$
}

\section{ABSTRACT}

A Cooperative Research and Development Agreement (CRADA) between Lockheed Martin Energy Research Corporation (LMER) and Smith \& Nephew Richards Inc. (S\&N ENT) of Bartlett, TN, was initiated in March 1997. The original completion date for the Agreement was March 25, 1998. The purpose of this work is to develop and commercialize net shape forming methods for directly creating dense hydroxylapatite (HA) ceramic otologic implants. The project includes three tasks: (1) modification of existing gelcasting formulations to accommodate HA slurries; (2) demonstration of gelcasting to fabricate green HA ceramic components of a size and shape appropriate to otologic implants; and (3) sintering and evaluation of the HA components.

$\mathrm{HA}$, both in dense and porous forms, is increasingly being used in bone replacement surgery because of its well-established biocompatibility. Otologic implants, because of the their small size, are costly to manufacture by the traditional approach of machining from dense HA ceramic billets. The gelcasting process holds the potential of making these components by injection molding or other net-shape forming method. The technological hurdles that must be overcome to demonstrate gelcasting as a viable technique for this application include: development of a biocompatible monomer/dispersant system suitable for HA powder; maintenance of dimensional tolerances in small components; and attainment of adequate green strength, green density, and economical process yields.

\section{OBJECTIVES}

The long-term objective of this CRADA is to develop and commercialize otologic implants manufactured via the gelcasting process, which was originally developed for high-temperature structural ceramic processing. Process variables that were examined include monomer and/or co-monomer systems, dispersants, initiator/catalyst systems, mold releases, and mold materials. The goal of studying these variables was to determine the chemistries necessary for the modification of the gelcasting process to ensure the successful sintering of a biocompatible dense hydroxyapatite (HA) implant that meets US Food and Drug Administration guidelines (FDA).

\section{ATTAINMENT OF OBJECTIVES}

Fully dense HA samples were prepared using the gelcasting process. The appropriate formulation was determined and samples were cast in a mold 
provided by S\&N ENT. After undergoing a prescribed drying regime, the samples were sintered in air to near full density. However, sintering in air resulted in a partial phase transformation of the HA to beta-tricalcium phosphate (B-TCP); this does not meet the FDA requirements for implantable HA products $(\geq 95 \% \mathrm{HA})$.

In order to minimize the phase transformation, samples were sintered in a wet nitrogen atmosphere. This greatly reduced the amount of B-TCP, but the FDA guidelines still had not been met. Finally, it was found that the debindering step (a necessary step with gelcast materials - it removes the organic binder) must be conducted in a steam atmosphere. By debindering in steam and sintering in wet nitrogen, a dense HA part with B-TCP $<5 \%$ was achieved.

\section{SPONSOR BENEFITS}

The DOE supplied funds for the work done by LMER through the DOE Office of Science (SC) Laboratory Technology Research Program Office. Traditionally, the gelcasting process has been applied to high-temperature structural ceramics such as silicon nitride for gas turbines. This CRADA has resulted in benefits to $S C$ that include the demonstration of the use of gelcasting to produce dense hydroxylapatite components with broad applications in biomedical implants; a better understanding of green machining of a traditionally weak ceramic; and a broader understanding of surface chemistry as related to the gelcasting process.

The CRADA project yielded several developments that are of substantial benefit for S\&N ENT and LMER. S\&N ENT could benefit from this work by increasing processing yields over traditional machining methods. S\&N ENT will have gained practical experience in net-shape forming technologies; decreased their manufacturing cycle time; and reduced scrap, thereby cutting the total product cost. Benefits to LMER include a greater understanding of the gelcasting process and of green machining, and a better understanding of gelcasting very small parts (prior to this work, gelcasting had been used for structural ceramics, i.e., large parts).

Benefits to DOE include the demonstration of gelcasting for producing dense HA components with broad applications in the biomedical sector and a greater understanding of the surface chemistries involved with gelcasting. Additionally, the green machining and new drying techniques examined during this work will be directly applicable to the ceramics industry at large, not just for biomedical applications.

\section{TECHNICAL DISCUSSION}

Development of gelcasting slurries

A. Powder Characterization

Initial studies involved characterization of the as-received HA powder (Rhone-Poulenc). Particle size analyses were performed using a Horiba LA700 Laser Scattering Particle Size Distribution Analyzer. Microstructural characterization was performed using a Hitachi S-4100 Scanning Electron 
Microscope (SEM) to examine particle morphology, uniformity, and integrity (hollow particles are not acceptable). Surface area measurements were made using a Quantachrome Autosorb 1.

Gelcasting typically utilizes ceramic particles on the order of $0.25-1.0$ microns. While larger particles can be used, the preferred size range allows for the optimum in particle loading. The as-received HA powder was 6-10 microns, so a milling study was undertaken to determine the ultimate particle size. Two hundred grams of as-received powder were placed in a one-gallon Bel-Art jug with $700 \mathrm{~g}$ de-ionized water and four kilograms of $3 \mathrm{~mm} \mathrm{ZrO}_{2}$ media. This jug was then placed on a standard ball mill and particle size analyses were performed at 30-minute intervals. It was found that after approximately 3 hours of wet ball-milling in de-ionized water, the average particle size had reached approximately 0.5 microns and did not reduce with further milling.

After reducing the particle size, an attempt was made to incorporate the milled powder into a gelcasting monomer system. This was completely unsuccessful. It was decided to measure the surface area of the powder. The results showed the surface area to be $-85 \mathrm{~m}^{2} / \mathrm{g}$, which is much too high to allow for incorporation into the slurry. A calcining study was undertaken to determine the optimal temperature and time needed to decrease the surface area to an acceptable limit. It was found that calcining in air at $900^{\circ} \mathrm{C}$ for two hours resulted in surface area measurements of $\leq 12 \mathrm{~m} 2 / \mathrm{g}$, much more amenable to gelcasting. However, if the powder is calcined after it is milled, grain growth is likely to occur, negating the milling process.

Currently, on as-received powder, calcining is performed first to reduce surface area and then the calcined powder is milled to reduce particle size. Vacuum filtration is used to remove water from the mill slurry. The resulting pancake is then placed in a drying oven to remove any water trapped within the powder. After the cake is fully dry, it is then broken up into powder by mortar and pestle grinding. The calcined, milled powder is stored in an airtight container until it is needed.

\section{B. Slurry Formulation}

There are several different parameters involved with a successful gelcasting slurry. These include: monomer system, dispersants, initiators, mold releases, and mold materials. Each of these parameters was studied with the processed hydroxyapatite powder. Table 1 describes each of the different systems examined using HA powder. Based on these studies, it was determined that the hydroxymethacrylamide (HMAM) monomer system with Darvan 821-C as the dispersant and AZIP as the initiator gave the best gel and green results, using an anodized aluminum mold with Polyester Parfilm as the release agent. 


\section{Component Fabrication}

To prepare a typical $100 \mathrm{ml}$ of 55 vol\% solids loaded HA slurry, $18.75 \mathrm{~g}$ of $20 \%$ HMAM is mixed with $1.77 \mathrm{~g}$ Darvan $821-\mathrm{A}, 177.05 \mathrm{~g}$ calcined, milled HA powder; and $0.94 \mathrm{~g}$ AZIP. The calcined, milled powder should be added incrementally: add 1/3 total powder and mill until fully incorporated; add 1/6 total powder and mill; add 1/8 total powder and mill; add 1/8 total powder and mill; add 1/8 total powder and mill; add $1 / 8$ total powder and mill. After the powder has been incorporated, the initiator may be added to the slurry and milled to ensure dispersion of the initiator into the slurry. The slurry may be ball milled or attritor milled for incorporation (for small batches in an attritor mill, the initiator may be added directly to the monomer premix). Regardless of which method is employed, de-airing is a necessary step after incorporation of the powder into the monomer system. The slurry must be decanted into an aspirator bottle and is then placed inside a dessicator under vacuum. The vacuum pulls the trapped air out of the slurry, thereby reducing the liklihood of flaws in the cast part(s). The prepared molds are filled with de-aired slurry via the aspirator bottle through the tube at the bottom to prevent any air bubbles from forming during filling. Molds are then placed in an oven at $55^{\circ} \mathrm{C}$ for one hour for gelation. After gelation, the mold may be removed from the drying oven and dismantled. It is acceptable to dismantle the mold under cool running water as the mold may be warm to the touch. When the gelled article has been removed, it may be washed under the cool water to remove any mold release from the surface. The gelled article must now be appropriately dried and the drying regime depends on the thickness of the part. If the thickest part of the part is $\leq 1 / 2^{\prime \prime}$, it may be dried in ambient conditions. However should the article be thicker than $1 / 4$ ", a prescribed drying regime must be followed to avoid introducing stresses within the part. Typical parts for this CRADA were small enough to dry in ambient conditions.

Drying is an important part of gelcasting. If an attempt is made to sinter a part before it is fully dry, cracking and sometimes catastrophic failure will occur during sintering. If the green part is kept under fairly steady humidity, it is simple to determine when the green part is dry. After taking the part out of the mold, it must be weighed. Weigh the part at intervals (typically days) and when it stops losing weight, it is dry and ready for further processing. During our studies with $\mathrm{HA}$ an alternative drying method was employed. After removing the gelled part from the mold and rinsing off any release residue, the part may be immersed in polyethylene glycol 400 (PEG400) for a short time (duration is dependent on part size) and then removed to ambient conditions. Due to osmosis, the water will be pulled out of the gelled part and into the PEG until either all the water is removed or until equilibrium is reached. This greatly reduces the amount of time usually needed for drying. Caution does need to be used when using this method, however, as a limit for its use in drying does appear. It was found that leaving a sample in for too long can result in the uptake of PEG into the sample.

After the part has dried, it may be subjected to machining if necessary. A machining study was undertaken using current machining parameters supplied by S\&N ENT as LMER's starting parameters. It was found that a green gelcast 
HA block could be machined at approximately twice the rate of S\&N ENT's current rate. A wall thickness test was performed and the thinnest walls ever machined in a gelcast block were achieved (approx. 2 mils thick). This test sample was sintered and it was found to retain its structural integrity after firing.

\section{Debindering and Sintering: Component Evaluation}

Gelcasting has a "typical" debindering schedule employed to remove the binder from a green part; this is usually carried out in air (Table 2). The sample is then sintered in the desired atmosphere to achieve density. For gelcast $\mathrm{HA}$ samples, the typical furnace schedule was $1^{\circ} \mathrm{C} / \mathrm{min}$ to $1250^{\circ} \mathrm{C}$ for 10 hours and then $1^{\circ} \mathrm{C} / \mathrm{min}$ to room temperature; the furnace atmosphere was wet nitrogen with a partial pressure of about $500 \mathrm{~mm} \mathrm{Hg}$. After firing, density measurements were made, indicating densities of $95-98 \%$ of the theoretical density HA. X-ray diffraction (XRD) was used to determine the HA phase content. A 4-axis powder diffractometer was used and the runs ranged from 60-700 minutes, covering $10-70^{\circ}$. XRD revealed that gelcast HA samples were below the acceptable limits set by the US Food \& Drug Administration (at least 95\% HA). Gelcast HA samples averaged a phase content of $88-90 \% \mathrm{HA}$ and close to 10 $11 \%$ B-TCP. Various measures were undertaken in an attempt to increase the HA phase content, including changing the ramp rates, the hold temperature, the hold time, and the partial pressure of water in the nitrogen atmosphere. Only minimal increases were made (average HA phase content increased by approx. $3 \%$ ). Finally, it was determined that performing the debindering step in air was providing enough kinetic energy to encourage the phase transformation to occur, even though literature cites approx. $900^{\circ} \mathrm{C}$ as the temperature of transformation. The last sample cast during this CRADA was debindered in a $100 \%$ steam atmosphere to $600^{\circ} \mathrm{C} / 1 \mathrm{hr}$. Sintering was carried out using the furnace schedule mentioned above. XRD data obtained from LMER's High Temperature Materials Laboratory User Center indicated a high percentage of the HA phase. The sample was sent to S\&N ENT for independent analysis to confirm LMER's results (Dr. lain Gibson from Queen Mary and Westfield College provided the analysis). The independent data did confirm LMER's results of 97$98 \%$ HA phase content. While this meets both the FDA's and S\&N ENT's requirements, it does leave room for optimization as typical S\&N ENT parts are approx. $99 \% \mathrm{HA}$.

\section{INVENTIONS}

No new inventions arose as a result of this CRADA.

\section{COMMERCIALIZATION}

Smith \& Nephew ENT is evaluating the results of this final, successful sample to determine if gelcast hydroxylapatite otologic implants will be introduced into their line. If cost-benefit analyses prove positive, negotiations will be undertaken to determine the best way to transfer the technology to the private sector. 


\section{PLANS FOR FUTURE COLLABORATION}

Smith \& Nephew ENT has expressed an interest in optimizing the gelcasting technology for otologic implants. The level of collaboration, if any, will depend on the results of their cost-benefit analyses.

\section{CONCLUSIONS}

The CRADA between LMER and Smith \& Nephew Richards, Inc. has been successfully completed. The gelcasting slurry was modified to accommodate the HA powder; samples were cast; debindering and sintering to $\geq 95 \%$ HA phase content was achieved. It was found that the as-received powder must be calcined and milled before use in the gelcasting process. The hydroxymethacrylamide monomer system was found to give a shelf-stable green part. Gelcast HA can be near net-shape cast or machined to shape. Debindering must occur in a steam atmosphere and sintering must occur in a wet nitrogen atmosphere. The resultant HA part is $\geq 95 \%$ HA phase content and meets USFDA guidelines. 
Table 1. List of parameters examined to optimize a gelcasting slurry of hydroxyapatite. PREMIXES

15\% MAM/PEG1000DMA (Methacrylamide/Polyethylene glycol dimethacrylate)

15\% MAM/MBAM (Methacrylamide/Methbisacrylamide)

15\% HMAM/MBAM (Hydroxymethacrylamide/Methbisacrylamide

HMAM/MAM (Hydroxymethacrylamide/Methacrylamide)

HMAM Hydroxymethacrylamide

\section{DISPERSANTS}

\begin{tabular}{|c|c|c|}
\hline Darvan 821-C & Darvan C & PVP-K15 20\% \\
\hline PVP-K30 20\% & DAXAD 30 & DAXAD 31 \\
\hline DAXAD 32 & DAXAD 34 & Disperse-AYD W22 \\
\hline Disperse-AYD W28 & Dolapix PC-33 & Dolapix PC-75 \\
\hline Solsperse 20000 & Arquad 2C-75 & Duramax D-3005 \\
\hline Duramax D-3007 & Gafac RE-610 & Gafac RS-410 \\
\hline Triton X-45 & Hypermer KD2 & $50 \%$ PEl-2000 \\
\hline Surfynol CT121 & Surfynol 104E & $5 \%$ Polyox N-3333 \\
\hline \multicolumn{3}{|l|}{ INITIATORS } \\
\hline \multicolumn{3}{|c|}{ AZIP 2,2'-Azobis[2-(2-imidazolin-2-yl)propane] dihydrochloride } \\
\hline \multicolumn{3}{|c|}{ AZAP 2,2'-Azobis(2-amidinopropane) dihydrochloride } \\
\hline \multicolumn{3}{|c|}{$10 \%$ APS/TEMED Ammonium persulfate/Tetramethylethylenediamine } \\
\hline \multicolumn{3}{|c|}{ NVP/AIBN N-vinyl-2-pyrrolidone/Azobis (2-methylpropionitrile) } \\
\hline \multicolumn{3}{|l|}{ MOLD RELEASES } \\
\hline Polyester Parfilm Ultra II & Mold Wiz AZN & Mold Wiz F-57 \\
\hline Mold Wiz F-57 NC & Vaseline & \\
\hline \multicolumn{3}{|l|}{ MOLD MATEBIALS } \\
\hline Anodized Aluminum & Wax & Glass \\
\hline
\end{tabular}


Table 2. Typical debindering furnace schedule for geicast parts.

\begin{tabular}{|c|c|}
\hline RAMP RATE & HOLD TEMP. \& TIME \\
\hline $0.5^{\circ} \mathrm{C} / \mathrm{min}$ & $150^{\circ} \mathrm{C} / 0 \mathrm{~min}$ \\
\hline $0.3^{\circ} \mathrm{C} / \mathrm{min}$ & $190^{\circ} \mathrm{C} / 0 \mathrm{~min}$ \\
\hline $1.2^{\circ} \mathrm{C} / \mathrm{min}$ & $335^{\circ} \mathrm{C} / 0 \mathrm{~min}$ \\
\hline $0.3^{\circ} \mathrm{C} / \mathrm{min}$ & $375^{\circ} \mathrm{C} / 0 \mathrm{~min}$ \\
\hline $1.9^{\circ} \mathrm{C} / \mathrm{min}$ & $600^{\circ} \mathrm{C} / 1-2$ hours \\
\hline Power off & ambient \\
\hline
\end{tabular}




\section{INTERNAL DISTRIBUTION}

1. A.D. McMillan, 4508 , MS 6087

2. R.J. Lauf, 4508, MS 6085

3. R. A. Bradley, 4500S, MS 6161

4. C.A. Valentine, 111 UNV, MS 6499

5. A. J. Luffman, 5002 , MS 6416

6. T.M. Rosseel, 4500 S, MS 6158

7-8. D. R. Hamrin, (Lab Records) 4500N, MS 6285

8. L.L. Horton, $4500 S$, MS 6132

9. T.A. Payne, 5002, MS 6416

\section{EXTERNAL DISTRIBUTION}

10. B. Beale, 2925 Appling Road, Smith \& Nephew ENT, Bartlett, TN 11. DOE Work for Others Office, MS G209

12. R. Johnson, 2925 Appling Road, Smith \& Nephew ENT, Bartlett, TN

13.S. J. Barish, DOE-HQ, SC-32, Energy Research Laboratory Technology Research Program, 19901 Germantown Road, Germantown, MD 208741290

14.P.L. Gorman, Department of Energy, Oak Ridge Operations Office, P.O. Box 2008, Oak Ridge, TN 37831-6269

15. W. M. Polansky, DOE, SC-32, 19901 Germantown Road, Germantown, MD 20874-1290

18-19. Office of Scientific and Technical Information, P. O. Box 62, Oak Ridge, TN 37831 
